\title{
Molecular identification and antimicrobial activity of endophytic fungi isolated from Heritiera fomes (Buch. -Ham), a mangrove plant of the Sundarbans
}

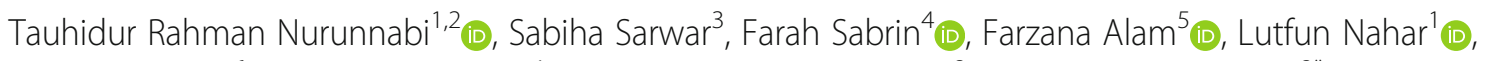
Hossain Sohrab ${ }^{6}$, Satyajit D. Sarker ${ }^{1}$ D, S. M. Mahbubur Rahman ${ }^{2}$ (D) and Morsaline Billah ${ }^{2^{*}}$ (D)

\begin{abstract}
Background: Endophytic fungi play a vital role in plant defense system by secreting various antimicrobial agents. To evaluate the antimicrobial activity of the endophytic fungi of the mangrove plant Heritiera fomes (Buch. -Ham), plants were collected from the Sundarbans, Bangladesh. The endophytic fungi were subsequently isolated and identified.

Results: Fifty-five endophytic fungi were isolated from the leaves, root, and bark of H. fomes (Buch. -Ham). Genomic DNA was extracted for PCR (polymerase chain reaction) by specific primers to multiply ITS region and sequences were determined. Nucleotide sequence data were submitted to the Genbank and accession number for each fungal strain was obtained. Antimicrobial activity of the ethyl acetate (EtOAc) and methanolic extracts of eleven species from both fermentation and mycelium, respectively, were analyzed by microtiter plate-based antimicrobial assay incorporating resazurin as an indicator of cell growth against two Gram-positive bacteria namely Staphylococcus aureus NCTC 12981 and Micrococcus luteus NCTC 7508, two Gram-negative bacteria namely Escherichia coli NCTC 12241 and Pseudomonas aeruginosa NCTC 12903, and a fungus Candida albicans ATCC 90028. All the endophytic fungal extracts exhibited antimicrobial activities against more than one-tested pathogenic microbial strains. Overall, methanolic extracts showed greater activity than EtOAc extracts. Pseudopestalotiopsis camelliae-sinensis, Pestalotiopsis microspora, and Penicillium copticola were the most active endophytic fungal strains and exhibited strong inhibitory activity against the microorganisms under investigation and their MIC values ranged from 0.0024 to $5.0 \mathrm{mg} / \mathrm{mL}$. Methanolic extracts of both P. camelliae-sinensis and P. microspora showed the highest antibacterial activity (MIC value of $0.0024 \mathrm{mg} / \mathrm{mL}$ ) against $P$. aeruginosa NCTC 12903 .
\end{abstract}

Conclusion: This study showed that the isolated and identified endophytic fungi from H. fomes (Buch. -Ham) could be potential sources of antimicrobial agents.

Keywords: Antimicrobial, Endophytic fungus, Mangrove plants, Heritiera fomes, The Sundarbans

\footnotetext{
* Correspondence: morsaline@yahoo.com

${ }^{2}$ Biotechnology and Genetic Engineering Discipline, Khulna University, Khulna 9208, Bangladesh

Full list of author information is available at the end of the article
}

\section{Springer Open}

(c) The Author(s). 2020 Open Access This article is licensed under a Creative Commons Attribution 4.0 International License, which permits use, sharing, adaptation, distribution and reproduction in any medium or format, as long as you give appropriate credit to the original author(s) and the source, provide a link to the Creative Commons licence, and indicate if changes were made. The images or other third party material in this article are included in the article's Creative Commons licence, unless indicated otherwise in a credit line to the material. If material is not included in the article's Creative Commons licence and your intended use is not permitted by statutory regulation or exceeds the permitted use, you will need to obtain permission directly from the copyright holder. To view a copy of this licence, visit http://creativecommons.org/licenses/by/4.0/. 


\section{Background}

In recent times, the chemistry of endophytic fungi has drawn considerable amount of interest as promising sources of new antibiotics and other therapeutic agents to face the emerging challenges in the arena of medicine and environment [1]. Many endophytic fungi have been reported to exhibit a number of interesting potential bioactivities through synthesis of diverse secondary metabolites by different metabolic pathways [2-4], viz. polyketides, isoprenoids, or derivatives of amino acids like phenols, steroids, xanthones, perylene derivatives, isocoumarins, quinines, furandiones, terpenoids, depsipeptides, and cytochalasines [5, 6]. Endophytes protect their hosts against various biotic and abiotic stresses by producing various bioactive compounds and provide unique mechanisms to support survival of the host plants [6]. Endophytic fungi reside in the intercellular spaces without showing any symptoms and do not cause adverse effects on their hosts [7]. Moreover, plants gain protection against invaded pathogenic microbes and herbivores because of the biosynthesis of bioactive secondary compounds by endophytic fungi [8]. Plant extracts have provided health benefits and long been used as main component of traditional medicines to fight against diseases and ailments [9]. However, many medicinal plants have been reduced from the natural habitat by over utilization, environmental deterioration, climate change, and ineffective conservation approaches. Several studies have shown that endophytic fungi can synthesis bioactive secondary compounds, analogous to the plant secondary metabolites [10]. Thus, endophytic fungi could be an alternative and untapped resource of potential bioactive compounds from the wild rather utilization of plant resources and their mass exploitation. They could be subjected to mass cultivation and further amenable to microbial fermentation techniques.

It has been well established that ecology of plants has enormous effect on the genetic diversity of the endophytes obtained from the plants and this has enabled them to produce different types of metabolites [11]. It is noteworthy to mention that a very few studies have been conducted to explore the diversity of mangrove endophytic fungi from the Sundarbans, the largest mangrove forest in the world [12-15]. We hypothesize that the endophytic fungi isolated from mangrove plants thriving at highly saline environment would produce a myriad of bioactive compounds to provide protection against salinity-induced abiotic-stress [16, 17], and these compounds may possess bioactive properties. Considering these facts, Heritiera fomes (Buch. -Ham), a primary mangrove plant and one of the dominant species of the world's largest mangrove forest the Sundarbans, has been chosen in the present study. In addition, this plant has never been studied for the presence of bioactive endophytic fungi and their activities. It is an evergreen moderate size tree growing abundantly in Sundarbans [18] and the trees can grow up to $25 \mathrm{~m}$ in height. The shining golden-brown scales are seen on the young branches of the trees. $H$. fomes is regarded as one of the important mangrove species having ethnomedicinal uses in traditional medicines. The people living in the vicinity of the mangrove forest use the plant extensively for treatment of various ailments. Common uses include treatments for gastrointestinal disorders including diarrhea, dysentery, constipation, indigestion, and stomachache. In addition, the plant is recommended for treatment of skin diseases including dermatitis, rash, eczema, boils, itch, scabies, sores, infections, and hepatic disorders including jaundice, hepatitis. Sometimes, traditional health practitioners use the plant for treating diabetes and goiter. It is a good insect repellent [19] and has wound healing activity [20]. H. fomes possesses significant antioxidant [21], antinociceptive, antihyperglycemic [22], antimicrobial [23], and anticancer activities [24]. It is also useful in cardiovascular diseases [25]. Though most of the findings have focused on these several bioactivities, endophytic fungi of the plant were never identified and characterized.

Therefore, the present study was carried out to isolate and identify endophytic fungi associated with mangrove plant H. fomes (Buch. -Ham) of the Sundarbans and subsequently subjected to evaluation of antimicrobial activity of the isolated fungal extracts against several pathogenic microorganisms.

\section{Methods}

\subsection{Collection of plant sample, preparation, and isolation of endophytic fungi}

Healthy and young roots, bark, and leaves of $H$. fomes (without any sign and symptoms of infection) were collected from the mangrove forest, the Sundarbans, Khulna, Bangladesh. The plant $H$. fomes was identified during sample collection based on the morphological characteristics described by Zabala [26] and a voucher specimen (TRN-KU-2017011) of this collection was retained. Plant samples were kept in sterile polythene bags under humid conditions at room temperature. Isolation of endophytic fungi was carried out by the procedure as described by Nurunnabi et al. [12]. Briefly, plant materials were washed thoroughly in sterile water to eliminate extraneous substances. The samples were then surface sterilized by sequentially immersing them in $70 \%$ ethanol for $30 \mathrm{~s}$ and $5 \%$ sodium hypochlorite solution for $1 \mathrm{~min}$ and finally rinsed with sterile distilled water. The samples were then surface-dried with sterile filter paper. Roots, bark, and leaves were cut into $0.5 \mathrm{~cm} \times 0.5$ $\mathrm{cm}$ pieces and placed on aqueous agar media (2\% agaragar in distilled water) supplemented with antibiotic 
streptomycin $(30 \mathrm{mg} / \mathrm{L})$ and incubated at $28 \pm 2{ }^{\circ} \mathrm{C}$ until fungal growth was initiated. The tips of the fungal hyphae were removed from the aqueous agar media and placed on potato dextrose agar (PDA) media. After 7 days of incubation, colony morphology was assessed to determine the purity of each fungal culture. The isolates were cultured several times on PDA to obtain final pure cultures and then transferred to PDA slants for storage until further study.

\subsection{Macroscopic, microscopic, and molecular identification of the fungal isolate}

Macroscopic, microscopic, and molecular techniques were employed to identify fungal endophytes according to the method described by Qadri et al. [27]. Macroscopically, the fungal morphology was studied by observing the colony features (shape, size, color, and hyphae) and microscopically, slides were prepared by mounting a small portion of the mycelium and then stained with lactophenol cotton blue. The slides were then examined by a compound microscope with a digital camera [28]. For molecular identification, fungal DNA was isolated using fungal DNA isolation kit (Cat-26200; NORGEN BIOTEK Corp., 3430 Schmon Parkway, Thorold, ON, Canada). Phylogenetic analysis of the isolated fungi was carried out by sequencing internal transcribed spacer (ITS) region of ribosomal gene. The ITS region of the fungi was amplified using the forward primer ITS4 $\left(5^{\prime}\right.$ TCCTCC GCTTATTGATATGC3') and reverse primer ITS5 $\left(5^{\prime}\right.$ GGAAGTAAAAGTCGTAACAAGG 3'), using polymerase chain reaction (PCR) [27].

The PCR reaction was performed in $50 \mu \mathrm{L}$ reaction volume comprising $10 \mu \mathrm{L}$ of $5 \mathrm{X}$ reaction buffer, $3 \mu \mathrm{L}$ of $1.5 \mathrm{M} \mathrm{MgCl}_{2}, 5 \mu \mathrm{L}$ of $10 \mathrm{mM}$ dNTP, $3 \mu \mathrm{L}$ of $100 \mathrm{pmol}$ primers, $26 \mu \mathrm{L}$ of distilled water, and $3 \mu \mathrm{L}(2 \mathrm{ng} / \mu \mathrm{L})$ of DNA. The PCR amplification was performed using 2720 PCR Thermo Cycler and the temperature profile was maintained as initial denaturation at $94{ }^{\circ} \mathrm{C}$ for $5 \mathrm{~min}$ followed by 39 cycles for each denaturation $\left(94^{\circ} \mathrm{C}\right.$ for 30 $\mathrm{s})$, annealing of the primers $\left(51^{\circ} \mathrm{C}\right.$ for $\left.30 \mathrm{~s}\right)$, and extension $\left(72^{\circ} \mathrm{C}\right.$ for $\left.2 \mathrm{~min}\right)$. The final extension was carried out at $72{ }^{\circ} \mathrm{C}$ for $5 \mathrm{~min}$ and held at $4{ }^{\circ} \mathrm{C}$. Then, amplified products $(10 \mu \mathrm{L})$ were verified by electrophoresis using $1.5 \%$ agarose gel for $45 \mathrm{~min}$ at $400 \mathrm{~mA}$ current flow. After carefully staining the gel with ethidium bromide, the amplified DNA fragments were observed under UV light transilluminator. The rest of the PCR amplified products $(40 \mu \mathrm{L}$ each) were purified according to requirement of Cambridge Genomic Services (CGS) (The University of Cambridge, UK) for sequencing. Consensus sequences $(\sim 522-560 \mathrm{bp})$ of $5.8 \mathrm{~S}$ rRNA were generated from forward and reverse sequence data using aligner software MEGA 7.0. Multiple BLASTN searches were made against the sequence available in the National
Center for Biotechnology Information (NCBI). Consensus sequences (5.8S rRNA) of isolated fungi were submitted in the GenBank of NCBI for acquisition of accession numbers. Unweighted pair group method with arithmetic mean (UPGMA) tree was constructed and pair wise genetic distance was obtained by the PAUP 4.0 software. Phylogenetic tree was constructed to show the genetic similarity among the isolated fungi. Briefly, the tree was constructed based on rDNA sequence (ITS1, $5.8 \mathrm{~S}$, and ITS 4) by using neighbor-joining method. The bootstrap consensus tree inferred from 1000 replicates. Branches corresponding to partitions reproduced in less than $50 \%$ bootstrap replicates are collapsed. All positions containing gaps and missing data were eliminated from the dataset (complete deletion option). There were 522 positions in total in the final dataset. Phylogenetic analyses were conducted by PAUP 4.0 software.

\subsection{Preparation of endophytic fungal extracts}

The fungal isolates were cultured into $(5 \times 250 \mathrm{~mL})$ conical flasks containing potato dextrose broth (PDB) for 28 days at $28{ }^{\circ} \mathrm{C}$ with $180 \mathrm{rpm}$ of continuous shaking. Fungal mycelia were separated through filtration (Whatman $^{\circ}$ qualitative filter paper, Grade 1; Sigma-Aldrich, USA) and the filtrates were extracted three times with an equal volume of ethyl acetate (EtOAc) using a separating funnel. The mycelium was grounded and dissolved in methanol for 2 days at dark and the mycelium was again separated by filtration. The EtOAc and the methanolic extracts were evaporated under reduced pressure at $40-45^{\circ} \mathrm{C}$ and $45-50{ }^{\circ} \mathrm{C}$, respectively, using rotary evaporator to obtain crude EtOAc and methanolic extracts [29].

\subsection{Antimicrobial screening}

Both EtOAc and the methanolic extracts of eleven isolated fungi were tested for their potential antimicrobial activities using the resazurin 96-well microtiter platebased in vitro antimicrobial assay described by Sarker et al. [30]. The antimicrobial activities were tested against two Gram-positive bacterial strains viz. Staphylococcus aureus (NCTC 12981) and Micrococcus luteus (NCTC 7508), and two Gram-negative viz. Escherichia coli (NCTC 12241) and Pseudomonas aeruginosa (NCTC 12903) as well as a fungal strain, Candida albicans (ATCC 90028). Ciprofloxacin and Nystatin were used as a positive control for bacterial and fungal strain, respectively. Microtiter plates were labeled and then A volume of $100 \mu \mathrm{L}$ of crude extract $(10 \mathrm{mg} / \mathrm{mL})$ in $10 \%(\mathrm{v} / \mathrm{v})$ DMSO was pipetted into the first row of the plate and remainder wells of the plate were filled aseptically with $50 \mu \mathrm{L}$ normal saline. Serial dilution technique was performed in such a way that each well contained $50 \mu \mathrm{L}$ of the test material in descending concentrations. To each 
well, $30 \mu \mathrm{L}$ of nutrient broth and $10 \mu \mathrm{L}$ of resazurin $(0.2$ $\mathrm{mg} / \mathrm{mL}$ ) were added as an indicator of cell growth. Finally, $10 \mu \mathrm{L}$ of microbial suspension $\left(5 \times 10^{5} \mathrm{cfu} / \mathrm{mL}\right)$ was added to each well and plates were loosely wrapped with cling film. Each plate had a set of controls: a column with the antibiotic as positive control as well as a column with $10 \mu \mathrm{L}$ of nutrient broth along with all solutions instead of $10 \mu \mathrm{L}$ microbial solution. The plates were replicated three times and incubated at $37^{\circ} \mathrm{C}$ for $18-24 \mathrm{~h}$ for any color change. Color change to pink or colorless indicated the positive microbial activity. The lowest concentration of the crude extract at which the change of color took place was considered the MIC value.

\subsection{Calculation and statistical analysis}

Colonization rate (CR) and isolation rate (IR) were calculated as percentages. For CR, total number of plant tissue segments infected by fungi divided by the total number of segments incubated, was used to indicate comparison of degrees of different tissues infected by endophytic fungi. IR was used to express the fungal richness in a given sample of plant tissue which was calculated as the numbers of isolates obtained from plant segments divided by the total number of segments incubated. The statistical analyses were done by Graph Pad Prism, version 6.01.

\section{Results}

\subsection{Isolation and identification of endophytic fungi}

A total of 55 endophytic fungi were isolated from 90 tissue segments (30 segments of each for roots, bark, and leaves) of $H$. fomes (Buch. -Ham). The isolation frequency of roots, bark and leaves were 50, 60, and 73\% [ $F$ $(2,6)=54.41, P<0.05]$, respectively. The isolation frequency of endophytic fungi from leaves was significantly higher than that of bark and roots. The colonization rate of endophytic fungal isolates varied significantly from each other $[F(7,16)=193.09, P<0.05]$ and it was found that Alternaria spp. showed highest colonization rate (25.6\%) while Nigrospora spp., Penicillium spp., and Pestalotia spp. showed 10.0\%, 8.9\%, and $7.8 \%$ colonization rates, respectively. The colonization rates for Epicoccum spp., Cladosporium spp., Bjerkandera spp., and Lasiodiplodia spp. were lower than the abovementioned isolates with the values of $3.3 \%, 2.2 \%, 2.2 \%$, and $1.1 \%$, respectively. After isolation of endophytes, isolates were grouped into eleven types based on their macroscopic and microscopic characteristics. Among the eleven isolated endophytic fungi from $H$. fomes (Buch. -Ham), light micrographs of two isolates are presented in Fig. 1. One from each group out of eleven groups was subjected to genomic DNA isolation. ITS region of the fungi was multiplied by ITS4 and ITS5 universal primers. Approximately $550 \mathrm{bp}$ of ITS region was generated by PCR reaction. ITS region amplified from genomic DNA of 11 endophytic fungi is shown in Fig. 2. PCR products were sent to Cambridge Genomic Services (CGS), the University of Cambridge, UK, for sequencing. By sequence determination and comparison with the sequences of Genbank database, the strains were identified to the species level (97 to 100\% homology to the bestmatching reference sequence). Obtained DNA sequences were submitted to the Genbank and accession numbers for each fungal isolate were obtained. Fifty-five endophytic fungi belonging eleven taxa were identified. Table 1 represents the isolated endophytic fungi from $H$. fomes (Buch. -Ham) with NCBI accession numbers. We found maximum similarity $(100 \%)$ in the isolates for P. copticola, A. alternata, and $L$. theobromae, respectively, with the sequences of reference strains deposited in Genbank in the BLAST match sequence comparison. However, L. theobromae and A. alternata were found to be the frequent genera obtained from $H$. fomes.
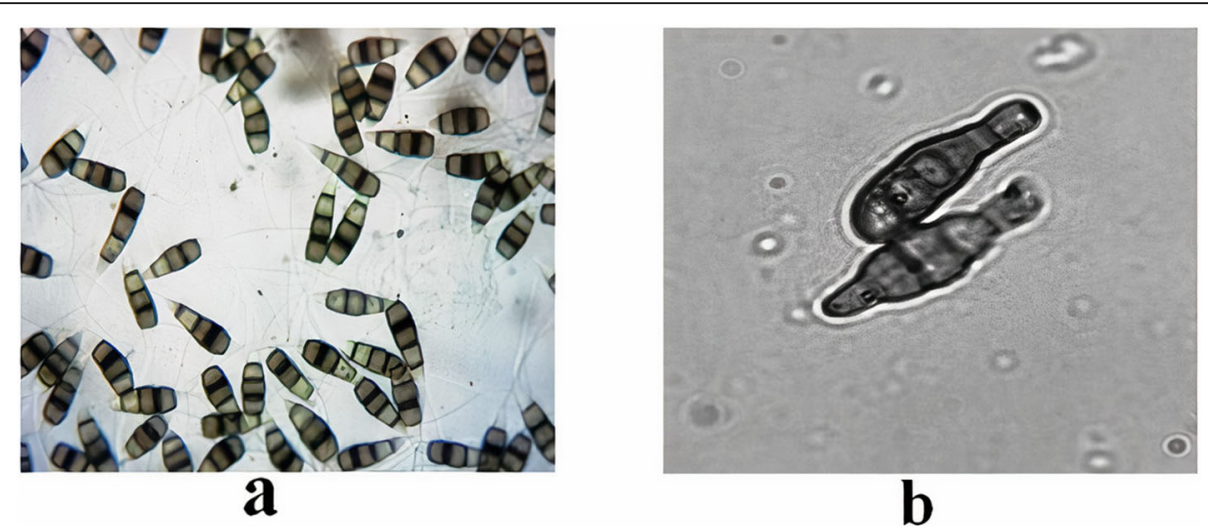

Fig. 1 Representative light micrographs of two endophytic fungi isolated from H. fomes (Buch. -Ham) on PDA media. a HfR14 (Neopestalotiopsis microspora). b HfR19 (Alternaria alternata) 


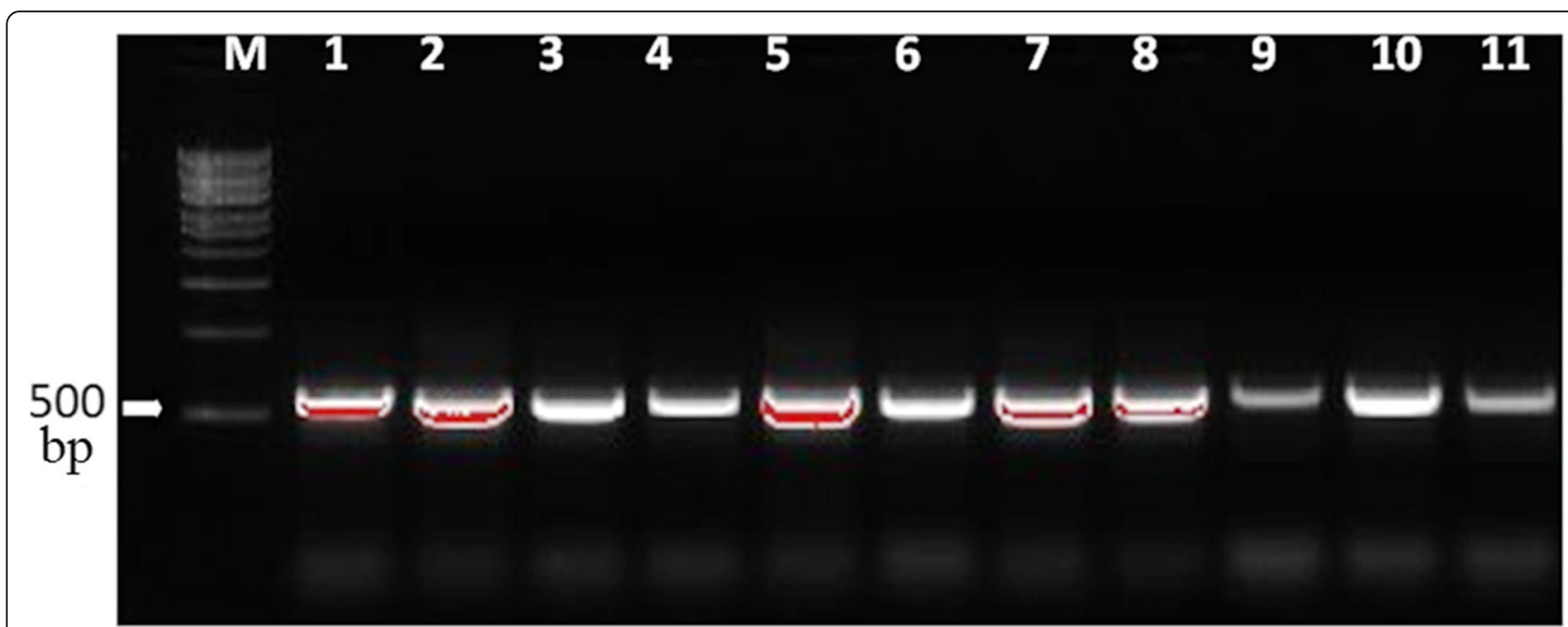

Fig. 2 PCR amplification of ITS region of endophytic fungi isolated from H. fomes (Buch. -Ham). Here, HfL8, $2=H f L 12,3=H f R 13,4=H f R 19,5=$ $\mathrm{HfR} 6,6=\mathrm{HfB} 9,7=\mathrm{HfB} 11,8=\mathrm{HfB} 3,9=\mathrm{HfR} 20,10=\mathrm{HfL} 18$, and $11=\mathrm{HfR} 21$ denote different fungal extracts collected from different plant materials where $\mathrm{H}$ stands for Heritiera, $\mathrm{f}$ for fomes, $\mathrm{L}$ for leaves, $\mathrm{R}$ for roots, and $\mathrm{B}$ for barks

\subsection{Phylogenetic tree and pair wise genetic distance} The phylogenetic tree constructed by PAUP 4.0 software showed two main branches (Fig. 3). It was represented that HfL8-MH220352 (L. theobromae), HfR20MH237826 (B. adusta), HfR21-MH220288 (E. nigrum), HfL18-MH220349 (C. tenuissimum), and HfR19MK757987 (A. alternata) had clustered in one group while rest of the fungi belonged to another group. HfB9MH211227 (N. sphaerica) and HfB11-MH211241 ( N. oryzae), HfR20-MH237826 (B. adusta), and HfR21MH220288 (E. nigrum) as well as HfL18-MH220349 (C. tenuissimum) and HfR19-MK757987 (A. alternata) have minimum genetic distance so they are close together.

Pair wise genetic distance (Table 2) expressed genetic distance among the endophytic fungi from $H$. fomes (Buch. -Ham). Maximum genetic distance (0.789) was found between HfL19 (A. alternata) and HfR20 (B. adusta). In contrast, minimum genetic distance was found between HfB9 (N. sphaerica) and HfB11 (N. oryzae).

\subsection{Antimicrobial activity of the methanolic and ethyl acetate extract of the endophytic fungi}

All the crude EtOAc and methanolic extracts of the isolates showed inhibitory effects against more than one tested organism (Table 3). Ciprofloxacin and Nystatin were used as positive control for bacteria and fungus, respectively. On average, the methanolic extracts were more effective on the tested microorganisms. It was found that about 97\% (48/55) of methanolic extracts showed better antimicrobial activities than 63\% (35/55) of ethyl acetate extracts. Methanolic and EtOAc extracts from N. microspora, $P$. camelliae-sinensis, and $P$.

Table 1 Edophytic fungi isolated from H. fomes (Buch. -Ham) with NCBI accession numbers

\begin{tabular}{|c|c|c|c|c|c|}
\hline \multirow{2}{*}{$\begin{array}{l}\text { Internal } \\
\text { code }\end{array}$} & \multirow[t]{2}{*}{ Name of the fungi } & \multirow{2}{*}{$\begin{array}{l}\text { Genbank } \\
\text { accession } \\
\text { number }\end{array}$} & \multicolumn{3}{|l|}{ BLAST match sequence } \\
\hline & & & Reference accession no. & Query length & Max iden. \\
\hline HfL12 & Pseudopestalotiopsis camelliae-sinensis & $\mathrm{MH} 180545$ & Pseudopestalotiopsis camelliae-sinensis KX757714.1 & 536 & $99 \%$ \\
\hline HfR14 & Pestalotiopsis microspora & MK778440 & Pestalotiopsis microspora MH712257.1 & 528 & $98 \%$ \\
\hline HfR19 & Alternaria alternata & MK757987 & Alternaria alternata KT898758.1 & 539 & $100 \%$ \\
\hline HfR6 & Alternaria brassicicola & MH203320 & Alternaria brassicicola KY310727.1 & 559 & $97 \%$ \\
\hline HfB9 & Nigrospora sphaerica & MH211227 & Nigrospora sphaerica KX256179.1 & 534 & $98 \%$ \\
\hline HfB11 & Nigrospora oryzae & $\mathrm{MH} 211241$ & Nigrospora oryzae & 530 & $99 \%$ \\
\hline HfB3 & Penicillium copticola & $\mathrm{MH} 211418$ & Penicillium copticola NR_121516.1 & 556 & $100 \%$ \\
\hline HfR20 & Bjerkandera adusta & $\mathrm{MH} 237826$ & Bjerkandera adusta MF120203.1 & 560 & $98 \%$ \\
\hline HfL 18 & Cladosporium tenuissimum & MH220349 & Cladosporium tenuissimum MF473305.1 & 532 & $99 \%$ \\
\hline HfR21 & Epicoccum nigrum & $\mathrm{MH} 220288$ & Epicoccum nigrum JF440590.1 & 525 & $99 \%$ \\
\hline HfL8 & Lasiodiplodia theobromae & MH220352 & Lasiodiplodia theobromae JX868719.1 & 522 & $100 \%$ \\
\hline
\end{tabular}

$H$, Heritiera; $f$, fomes; $L$, leaves; $R$, root; $B$, bark 


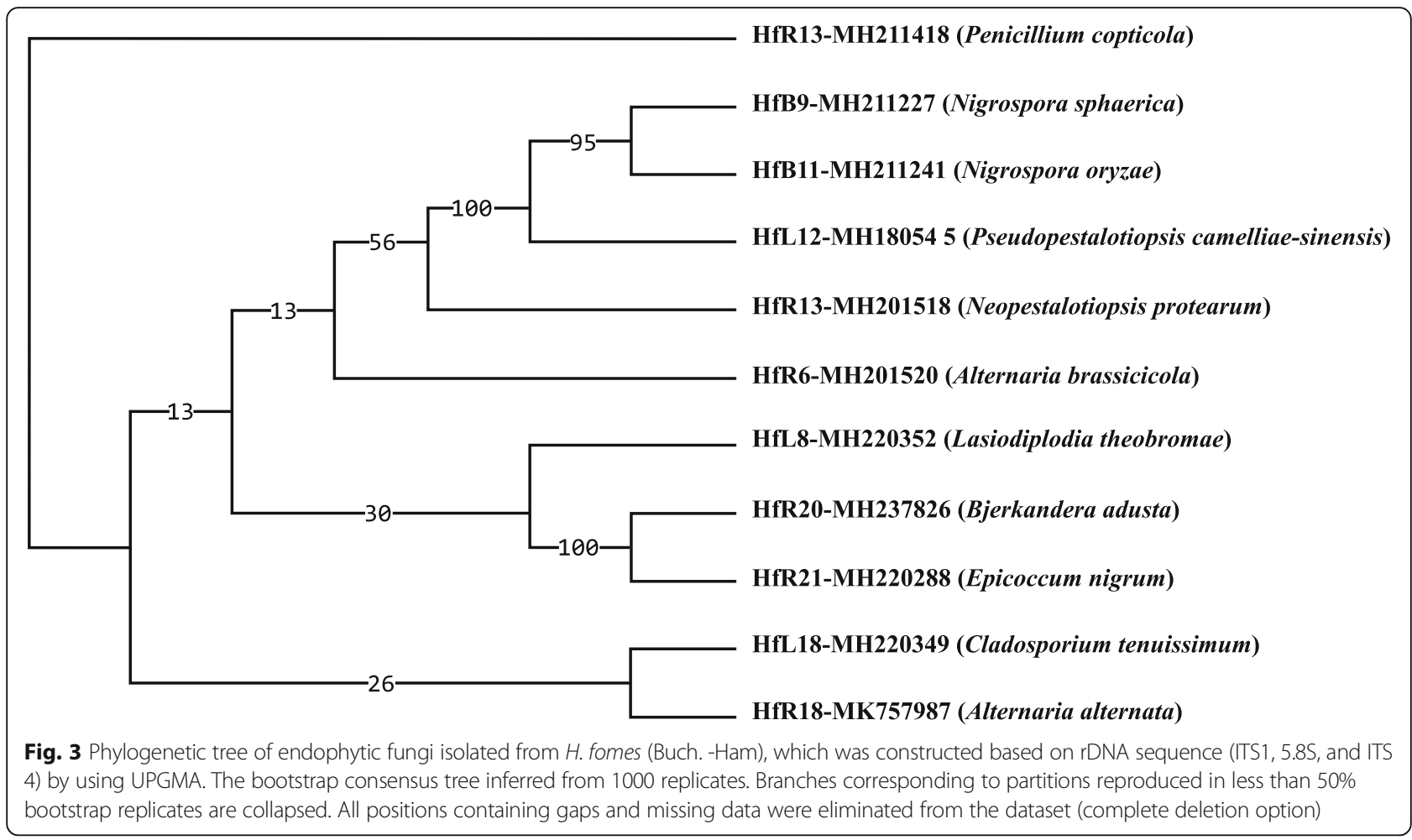

copticola showed antimicrobial effect on all tested microorganisms and only the methanolic extract from $N$. sphaerica and $N$. oryzae showed activity against all of them. The methanolic extract from $N$. microspora and $P$. camelliae-simitheae confirmed the highest activity with an MIC of $0.0024 \mathrm{mg} / \mathrm{mL}$ against $P$. aeruginosa (NCTC 12903). The fungal extract displayed activity against $P$. aeruginosa (NCTC 12903) and S. aureus (NCTC 12981) (MIC ranged from 10 to $0.00024 \mathrm{mg} / \mathrm{mL}$ ). Only $40 \%$ (9/ $22)$ and $59 \%(13 / 22)$ of the extracts showed activity against E. coli (NCTC 12241) and C. albicans (ATCC
90028), respectively. For M. luteus (NCTC 7508), 81\% $(18 / 22)$ of the extracts exhibited antibacterial activity. EtOAc and methanolic extracts from $P$. copticola showed significant effect against M. luteus (NCTC 7508) with MIC value of $0.0097 \mathrm{mg} / \mathrm{mL}$ in both cases.

\section{Discussion}

Endophytic fungi have been reported from a variety of plant species that contribute to the diversity of microorganisms in the ecosystems. Inside the plant, the fungi produce various biologically active compounds which

Table 2 Pair wise genetic distance of eleven endophytic fungi isolated from $H$. fomes (Buch. -Ham)

\begin{tabular}{|c|c|c|c|c|c|c|c|c|c|c|c|}
\hline & HfB3 & HfB9 & HfB11 & HfL8 & HfL12 & HfL18 & HfR6 & HfR13 & HfR19 & HfR20 & HfR21 \\
\hline HfB3 & - & & & & & & & & & & \\
\hline HfB9 & 0.695 & - & & & & & & & & & \\
\hline HfB11 & 0.693 & 0.317 & - & & & & & & & & \\
\hline HfL8 & 0.733 & 0.745 & 0.731 & - & & & & & & & \\
\hline HfL12 & 0.739 & 0.411 & 0.419 & 0.747 & - & & & & & & \\
\hline HfL18 & 0.699 & 0.716 & 0.701 & 0.741 & 0.733 & - & & & & & \\
\hline HfR6 & 0.747 & 0.766 & 0.779 & 0.745 & 0.758 & 0.766 & - & & & & \\
\hline HfR13 & 0.704 & 0.714 & 0.712 & 0.772 & 0.628 & 0.724 & 0.722 & - & & & \\
\hline HfR19 & 0.716 & 0.747 & 0.764 & 0.760 & 0.749 & 0.722 & 0.731 & 0.766 & - & & \\
\hline HfR2O & 0.758 & 0.731 & 0.756 & 0.762 & 0.762 & 0.789 & 0.758 & 0.764 & 0.758 & - & \\
\hline HfR21 & 0.747 & 0.735 & 0.722 & 0.743 & 0.756 & 0.770 & 0.760 & 0.783 & 0.752 & 0.429 & - \\
\hline
\end{tabular}

$H$, Heritiera; $f$, fomes; $L$, leaves; $R$, root; $B$ bark 
Table 3 Minimum inhibitory concentration (MIC, in mg/mL) of ethyl acetate (EtOAc) and methanolic (MeOH) extracts of 11 different endophytic fungi from $H$. fomes (Buch. -Ham)

\begin{tabular}{|c|c|c|c|c|c|c|}
\hline \multirow{2}{*}{$\begin{array}{l}\text { Name of the endophytic } \\
\text { fungi }\end{array}$} & \multirow[t]{2}{*}{ Extract } & \multicolumn{2}{|c|}{ Gram-negative bacteria } & \multicolumn{2}{|c|}{ Gram-positive bacteria } & \multirow{2}{*}{$\begin{array}{l}\text { Fingal Strain } \\
\text { C. albicans (ATCC } \\
\text { 90028) }\end{array}$} \\
\hline & & $\begin{array}{l}\text { E. coli (NCTC } \\
\text { 12241) }\end{array}$ & $\begin{array}{l}\text { P. aeruginosa (NCTC } \\
\text { 12903) }\end{array}$ & $\begin{array}{l}\text { M. luteus (NCTC } \\
7508 \text { ) }\end{array}$ & $\begin{array}{l}\text { S. aureus (NCTC } \\
12981 \text { ) }\end{array}$ & \\
\hline \multirow{2}{*}{$\begin{array}{l}\text { Pseudopestalotiopsis } \\
\text { camelliae-sinensis }\end{array}$} & EtOAc & 0.312 & 0.312 & 0.312 & 0.125 & 0.625 \\
\hline & $\mathrm{MeOH}$ & 5 & 0.0024 & 0.625 & 0.312 & 0.312 \\
\hline \multirow[t]{2}{*}{ Pestalotiopsis microspora } & EtOAc & 5 & 0.125 & 0.25 & 0.25 & 0.312 \\
\hline & $\mathrm{MeOH}$ & 0.25 & 0.0024 & 0.625 & 0.125 & 0.625 \\
\hline \multirow[t]{2}{*}{ Alternaria alternata } & EtOAc & NA & 2.5 & 1.25 & 10 & NA \\
\hline & $\mathrm{MeOH}$ & NA & 1.25 & 0.625 & 5 & 2.5 \\
\hline \multirow[t]{2}{*}{ Alternaria brassicicola } & EtOAc & NA & 5 & 1.25 & 10 & NA \\
\hline & $\mathrm{MeOH}$ & NA & 1.25 & 1.25 & 5 & 10 \\
\hline \multirow[t]{2}{*}{ Nigrospora sphaerica } & EtOAc & NA & 5 & NA & 5 & NA \\
\hline & $\mathrm{MeOH}$ & 10 & 0.625 & 1.25 & 0.625 & 10 \\
\hline \multirow[t]{2}{*}{ Nigrospora oryzae } & EtOAc & NA & 5 & NA & 5 & NA \\
\hline & $\mathrm{MeOH}$ & 10 & 0.625 & 1.25 & 0.625 & 5 \\
\hline \multirow[t]{2}{*}{ Penicillium copticola } & EtOAc & 2.5 & 0.625 & 0.0097 & 0.625 & 1.25 \\
\hline & $\mathrm{MeOH}$ & 2.5 & 0.625 & 0.0097 & 0.312 & 1.25 \\
\hline \multirow[t]{2}{*}{ Bjerkander aadusta } & EtOAc & NA & NA & NA & 5 & 10 \\
\hline & $\mathrm{MeOH}$ & NA & 5 & 1.25 & 10 & NA \\
\hline \multirow[t]{2}{*}{ Cladosporium tenuissimum } & EtOAc & NA & 1.25 & 2.5 & 10 & NA \\
\hline & $\mathrm{MeOH}$ & 5 & 2.5 & 2.5 & 5 & NA \\
\hline \multirow[t]{2}{*}{ Epicoccum nigrum } & $\mathrm{EtOAc}$ & NA & 2.5 & 10 & 10 & NA \\
\hline & $\mathrm{MeOH}$ & NA & 2.5 & 5 & 5 & 2.5 \\
\hline \multirow[t]{2}{*}{ Lasiodiplodia theobromae } & EtOAc & NA & 0.62 & NA & 2.5 & NA \\
\hline & $\mathrm{MeOH}$ & NA & 0.62 & 5 & 1.25 & 2.5 \\
\hline Ciprofloxacin & & 0.00049 & 0.00012 & 0.00098 & 0.00098 & NT \\
\hline Nystatin & & NT & NT & NT & NT & 0.00098 \\
\hline
\end{tabular}

NA no activity, NT not tested, EtOAc ethyl acetate extract, $\mathrm{MeOH}$ methanolic extract

play versatile roles in their inherent surroundings. Mangroves plants can thrive in a unique habitat with high microbial and fungal competitions and brackish tidal environment. The association with endophytic fungi and mangrove plants confers protection from unsympathetic environmental conditions and allow them to cope with saprobic fungi [31]. In an extensive review, Liu et al. (2007) documented more than 200 species of mangrove endophytic fungi and predominant species included Alternaria, Aspergillus, Cladosporium, Clolletotrichum, Fusarium, Paecilomyces, Penicillium, Pestalotiopsis, Phoma, Phomopsis, Phyllosticta, and Trichoderma [32]. They also reported that most endophytic fungi could originate from wide range of hosts which a few might have single host [33]. In another study, Colletolrichum spp. was found to be one of the most abundant endophytic fungal species in Indian mangrove plant community [34]. In Pichavaram mangrove ecosystem, several endophytic fungal genera have been reported from the leaves of various mangrove plants [35]. Our study is also in good agreement with these previous studies as we have isolated and identified several distinctive endophytic fungal species in different genera. However, in our case, Alternaria spp. was the most dominant species followed by Nigrospora spp. and Penicillium spp.

Although we identified the endophytic fungus based on morphological characteristics, however, this type of identification is presumptive and requires fair bit of experience. Therefore, in addition to this, we chose nucleotide sequence analysis for more accurate identification, due to its simplicity and straightforward nature of operation. In the present study, ITS region was chosen because of its location between two highly conserved genes, which code for $18 \mathrm{~S}$ and $28 \mathrm{~S}$ rRNA. The ITS regions circumscribe two noncoding regions ITS1 and ITS2, which are separated by the highly conserved $5.8 \mathrm{~S}$ rRNA gene [36]. The ITS1 and ITS2 regions are more variable than the other adjacent rRNA gene sequences 
[37] and, therefore, offer a better identification of closely related species. By sequence determination and comparison with the sequences of Genbank database, all the strains were identified to the species level (97 to 100\% homology to the best-matching reference sequence).

On average, methanolic extracts were found to be the most effective, except for $P$. camelliae-sinensis and $N$. protearum where the extracts of ethyl acetate were more active than that of methanolic extracts. Ethyl acetate extracts from these two fungi showed better activities against the test microorganisms. In other cases, methanol was found to be suitable and effective as an extraction medium and methanolic extracts showed better antimicrobial activities than ethyl acetate against the tested microbes. The data is supported by the pronounced antimicrobial effects shown by methanolic extracts over ethyl acetate extracts, which is evident from the level of inhibition of growth for various microorganisms under investigation and can be associated with the change of the color for resazurin. The change of the color in the well is inferred that the metabolic activity of live microbes released $\mathrm{CO}_{2}$ and $\mathrm{O}_{2}$ which became pink and fluorescent when reduced to resorufin by oxidoreductase activity. Resorufin is further reduced to hydroresazurin and becomes colorless. Due to inhibition of bacterial action by potential fungal extracts, the dye color stays unaffected in the well. From this assay, fungal extracts which possessed antimicrobial potential were identified rapidly [30]. In a study of Brazilian mangrove plant Laguncularia racemosa (L.) Gaertn, seventy endophytic fungal strains were isolated from leaves and antimicrobial properties of their ethyl acetate extracts were evaluated against $S$. aureus, Bacillus subtilis, E. faecalis, $M$. luteus, E. coli, and P. aeruginosa. The results showed that endophytic fungi strains were able to produce secondary metabolites with antimicrobial activity, and the crude extracts from Aspergillus niger, Curvularia pallescens, Guignardia bidwelii, Paecilomyces variotii, and Mycelia sterilia showed the best results [38]. In another study, Bhimba et al. (2012) investigated the antibacterial activity of marine-derived fungi Phoma herbarum, isolated from mangrove leaves. The isolated fungi showed potent activity against $M$. luteus and Vibrio cholerae [39]. Similarly, a mangrove fungi $P$. microspora VB5 was isolated from the leaves of two mangrove plants from Pichavaram mangrove forest in Southeast coast of India [40]. The crude extracts of this endophytic fungi showed strong antimicrobial activity against $B$. subtilis (ATCC 6633), S. aureus (ATCC 25923), E. coli (ATCC 25922), and P. aeruginosa (ATCC 27853) by agar well diffusion method.

\section{Conclusion}

In this study, we successfully isolated and identified 11 different species of endophytic fungi belonging to 9 different genera. All the isolates are moderately active against tested microorganisms. However, further studies could be initiated with $N$. microspora, $P$. camelliaesinensis, and P. copticola for potential for bioactive compounds as our results showed promising antimicrobial activities with these endophytic fungi. The findings of this study also suggested that endophytes from harsh and competitive environments, such as mangrove ecosystem, might be an attractive source for bioprospecting of new anti-infective compounds.

\section{Abbreviations}

CGS: Cambridge Genomic Services; CR: Colonization rate; EtOAc: Ethyl acetate; IR: Isolation rate; ITS: Internal transcribed spacer; NCBI: National Center for Biotechnology Information; PCR: Polymerase chain reaction; PDA: Potato dextrose agar; UPGMA: Unweighted pair group method with arithmetic mean

\section{Acknowledgements}

The authors acknowledge the assistance of Md. Rejaul Islam, Professor, Agrotechnology Discipline, Khulna University, Khulna, for microscopy of the fungal species. The authors also acknowledge Dr. Md. Rabiul Alom, Associate Professor, Forestry and Wood Technology Discipline, Khulna University, Khulna, for taxonomic identification of the plant.

\section{Authors' contributions}

Conceptualization: MMB, SMMR, SDS, and MHS. Methodology: MMB and TRN. Formal analysis and investigation: TRN. Data and statistical analysis: TRN, FS, and FA. Writing —original draft preparation: TRN, FS, SS, and FA. Writing - review and editing: MMB, TRN, FS, SS, and FA. Funding acquisition: MMB, SMMR, SDS, MHS, and LN. Resources: MMB, SMMR, SDS, MHS, and LN. Supervision: MMB, SMMR, SDS, MHS, and LN. All authors have read and approved the manuscript.

\section{Funding}

This research was conducted by the financial support of Robert S McNamara Fellowship Programme from the World Bank to Tauhidur Rahman Nurunnabi and as a part of INSPIRE Project on "Bioprospecting medicinal plants of the Sundarbans, the world's largest mangrove forest, in search for new medicine." In addition, L Nahar gratefully acknowledges the financial support of the European Regional Development Fund_-Project ENOCH (No. CZ.02.1.01/0.0/0.0/16_019/0000868).

Availability of data and materials

Not applicable

Ethics approval and consent to participate

Not applicable

Consent for publication

Not applicable

Competing interests

The authors declare that they have no competing interests.

\section{Author details}

${ }^{1}$ Medicinal Chemistry and Natural Products Research Group, School of Pharmacy and Biomolecular Sciences, Liverpool John Moores University, James Parsons Building, Byrom Street, Liverpool L3 3AF, UK. ${ }^{2}$ Biotechnology and Genetic Engineering Discipline, Khulna University, Khulna 9208,

Bangladesh. ${ }^{3}$ Environmental Science and Technology, Jashore University of Science and Technology, Jashore 7408, Bangladesh. ${ }^{4}$ Department of Biotechnology and Genetic Engineering, Mawlana Bhashani Science and Technology University, Santosh, Tangail 1902, Bangladesh. ${ }^{5}$ Department of Genetic Engineering and Biotechnology, Jagannath University, Dhaka, Bangladesh. ${ }^{6}$ Pharmaceutical Sciences Research Division, BCSIR Laboratories, Dhaka 1205, Bangladesh. 
Received: 13 May 2020 Accepted: 22 October 2020 Published online: 09 December 2020

\section{References}

1. Jon C, Michael AF, Christopher TW (2006) New antibiotics from bacterial natural products. Nat Biotechnol 24(12):1541-1550. https://doi.org/10.1038/ nbt1266

2. Breen JP (1994) Acremonium endophyte interactions with enhanced plant resistance to insects. Annu Rev Entomol 39:401-423. https://doi.org/10. 1146/annurev.en.39.010194.002153

3. Schulz B, Rommert AK, Dammann U, Aust HJ, Strack D (1999) The endophyte-host interaction: a balanced antagonism? Mycol Res 103:12751283. https://doi.org/10.1017/S0953756299008540

4. Tan RX, Xou WX (2001) Endphytes: a rich source of functional metabolites. Nat Prod Rep 18:448-459. https://doi.org/10.1039/B1009180

5. John J, Krohn K, Flore U, Aus HJ, Draeger S, Schulz B (1999) Biologically active secondary metabolites from fungi, oidiolactones A-F, labdane diterpene derivatives isolated from oidiodendron truncate. J Nat Prod 62: 1218-1221. https://doi.org/10.1021/np9804987

6. Konig G, Wright AD, Draeger S, Aust HJ, Schulz B (1999) Geniculol, a new biologically active diterpene from the endophytic fungus Geniculosporium sp 1. J Nat Prod 62:155-157. https://doi.org/10.1021/np9802670

7. Hyde KD, Soytong K (2008) The fungal endophyte dilemma. Fungal Divers 33:163-173

8. Sette L, Passarini M, Delarmelina C, Salati F, Duarte M (2006) Molecular characterization and antimicrobial activity of endophytic fungi from coffee plants. World J Microbiol Biotechnol 22(11):1185-1195. https://doi.org/10. 1007/s11274-006-9160-2

9. Kathuria V, Kaushik N (2006) Evaluation of insecticidal property of some plant species against Helicoverpa armigera. Indian J Agric Sci 76:614-617

10. Owen NL, Hundley N (2004) Endophytes-the chemical synthesizers inside plants. Sci Prog 87:79-99

11. Martiny JBH, Martiny JB, Bohannan BJ, Brown JH, Colwell RK, Fuhrman JA, Green JL, Horner-Devine MC, Kane M, Krumins JA, Kuske CR, Morin PJ, Naeem S, Ovreås L, Reysenbach AL, Smith VH, Staley JT (2006) Microbial biogeography: putting microorganisms on the map. Nat Rev Microbiol 4: 102-112. https://doi.org/10.1038/nrmicro1341

12. Nurunnabi TR, Nahar L, Al-Majmaie $S$ et al (2018) Anti-MRSA activity of oxysporone and xylitol from the endophytic fungus Pestalotia sp. growing on the Sundarbans mangrove plant Heritiera fomes. Phytother Res 32(2): 348-354. https://doi.org/10.1002/ptr.5983

13. Nurunnabi TR, Al-Majmaie S, Nakouti I, Nahar L, Rahman SMM, Sohrab MH et al (2018) Antimicrobial activity of kojic acid from the endophytic fungus Colletotrichum gloeosporioides isolated from Sonneratia apetala, a mangrove plant of the Sundarbans. Asian Pac J Trop Med 11(5):350-354. https://doi. org/10.4103/1995-7645.233183

14. Nurunnabi TR, Al-Majmaie S, Nahar L, Nakouti I, Rahman SMM, Sohrab MH et al (2019) Sonneratinone: a new antimicrobial benzofuranone derivative from the endophytic fungus Aspergillus niger isolated from the mangrove plant Sonneratia apetala Buch.- Ham. Trends Phytochem Res 3(3):222-227

15. Nurunnabi TR, Sabrin F, Sharif DI, Nahar L, Sohrab MH, Sarker SD et al (2020) Antimicrobial activity of endophytic fungi isolated from the mangrove plant Sonneratia apetala (Buch.-Ham) from the Sundarbans mangrove forest. Adv Trad Med. https://doi.org/10.1007/s13596-019-00422-9 Article in Press

16. Waqas M, Khan AL, Kamran M, Hamayun M, Kang SM, Kim YH, Lee IJ (2012) Endophytic fungi produce gibberellins and indoleacetic acid and promotes host-plant growth during stress. Molecules 17:10754-10773. https://doi.org/ 10.3390/2Fmolecules170910754

17. Ali S, Charles TC, Glick BR (2014) Amelioration of high salinity stress damage by plant growth-promoting bacterial endophytes that contain ACC deaminase. Plant Physiol Biochem 80:160-167. https://doi.org/10.1016/j. plaphy.2014.04.003

18. Mahmud I, Islam MK, Saha S, Barman AK, Rahman MM, Anisuzzman M, Rahman T, Al-Nahian A, Jahan R, Rahmatullah M (2014) Pharmacological and ethnomedicinal overview of Heritiera fomes: future prospects. Int Sch Res Notices 2014:938543, 12 pages. https://doi.org/10.1155/2014/938543

19. Mollik MAH, Hossan MSH, Paul AK, Taufiq-Ur-Rahman M, Jahan R, Rahmatullah M (2010) A comparative analysis of medicinal plants used by folk medicinal healers in three districts of Bangladesh and inquiry as to mode of selection of medicinal plants. Ethnobot Res Appl 8:195-218
20. Patra JK, Thatoi N (2011) Metabolic diversity and bioactivity screening of mangrove plants: a review. Acta Physiol Plant 33(4):1051-1061. https://doi. org/10.1007/s11738-010-0667-7

21. Wangensteen $H$, Alamgir M, Duong GM, Gronhaug TE, Samuelsen AB, Malterud KE (2009) Chemical and biological studies of medicinal plants from the Sundarbans mangrove forest. In: Eddouks M (ed) Advances in phytotherapy research, vol 1. Research Signpost, Kerala

22. Ali M, Nahar K, Sintaha M, Khaleque HN, Jahan FI, Biswas KR (2011) An evaluation of antihyperglycemic and antinociceptive effects of methanol extract of Heritiera fomes Buch- Ham. (Sterculiaceae) barks in Swiss albino mice. Adv Nat Appl Sci 5(2):116-121

23. Wangensteen H, Dang HCT, Uddin SJ, Alamgir A, Malterud KE (2009) Antioxidant and antimicrobial effects of the mangrove tree Heritiera fomes. Nat Prod Commun 4(3):371-376

24. Patra JK, Thatoi H (2013) Anticancer activity and chromatography characterization of methanol extract of Heritiera fomes Buch. Ham., a mangrove plant from Bhitarkanika, India. Ori Pharm Experi Med 13(2):133142. https://doi.org/10.1007/s13596-013-0113-7

25. Mollik MAH, Faruque MR, Badruddaza M, Chowdhury A, Rahman MS (2009) Medicinal plants from Sundarbans used for the prevention of cardiovascular diseases: a pragmatic randomized ethnobotanical survey in Khulna division of Bangladesh. Eur J Integr Med 1(4):231-232. https://doi.org/10.1016/j.eujim.2009.08.018

26. Zabala NQ (1990) Silviculture of species. Field document no. 14. In: Development of professional education in the Forestry Sector of Bangladesh, UNDP/FAO Project BGD/85/011

27. Qadri M, Johri S, Shah BA, Khajuria A, Sidiq T, Lattoo SK, Abdin MZ, Riyaz-UIHassan S (2013) Identification and bioactive potential of endophytic fungi isolated from selected plants of the Western Himalayas. Springer Plus 2:114. https://doi.org/10.1186/2193-1801-2-8

28. Gaddeyya G, Niharika PS, Bharathi P, Ratna KPK (2012) Isolation and identification of soil mycoflora in different crop fields at salur Mandal. Adv Appl Sci Res 3(4):2020-2026

29. Wang FW, Jiao RH, Cheng AB, Tan SH, Song YC (2006) Antimicrobial potentials of endophytic fungi residing in Quercus variabilis and brefeldin A obtained from Cladosporium sp. World J Microbiol Biotechnol 235:79-83. https://doi.org/10.1007/s11274-006-9195-4

30. Sarker SD, Nahar L, Kumarasamy Y (2007) Microtitre-plate-based antibacterial assay icorporating resazurin as an indicator of cell growth and its application in the in vitro antibacterial screening of phytocheicmals. Methods 42:321-324. https://doi.org/10.1016/j.ymeth. 2007.01.006

31. Maria GL, Sridhar KR, Raviraja SN (2005) Antimicrobial and enzyme activity of mangrove endophytic fungi of Southwest coast of India. J Agric Technol 1:67-80

32. Liu AR, Wu XP, Tong XU (2007) Research advances in endophytic fungi of mangrove. Chin J Appl Ecol 18:912-918

33. Thatoi H, Bikash C, Behera BC, Mishra RR (2013) Ecological role and biotechnological potential of mangrove fungi: a review. Mycology 4(1):5471. https://doi.org/10.1080/21501203.2013.785448

34. Kumaresan V, Suryanarayanan TS (2001) Occurrence and distribution of endophytic fungi in a mangrove community. Mycol Res 105:1388-1391. https://doi.org/10.1017/S0953756201004841

35. Gayathria S, Balagurunathanb R, Radhakrishnana M, Kathiresan K (2009) Mangroves, a potential source for microbial endophytes too! Seshaiyana 17:3-4

36. Crouch JA, Clarke BB, White JW, Hillman BI (2009) Systematic analysis of the falcate-spored graminicolous Colletotrichum and a description of six new species of the fungus from warm-season grasses. Mycologia 101:717-732. https://doi.org/10.3852/08-230

37. Ciardo DE, Schar G, Bottger EC, Altwegg M, Bosshard PP (2006) Internal transcribed spacer sequencing versus biochemical profiling for identification of medically important yeasts. J Clin Microbiol 44(1):77-84. https://doi.org/ 10.1128/JCM.44.1.77-84.2006

38. Silva MRO, Almeida AC, Arruda FVF, Gusmao N (2011) Endophytic fungi from Brazilian mangrove plant Laguncularia racemosa (L.) Gaertn. (Combretaceae): their antimicrobial potential. In: Mendez-Vilas A (ed) Science against microbial pathogens: communicating current research and technological advances. Formatex, Badajoz, pp 1260-1266 
39. Bhimba BV, Pushpam AC, Arumugam P, Prakash S (2012) Phthalate derivatives from the marine fungi Phoma herbarum VB7. Int J Biol Pharma Res 3:507-512

40. Joel EL, Bhimba BV (2012) Fungi from Mangrove plant: their antimicrobial and anticancer potentials. Int J Pharm Pharm Sci 4:139-142

\section{Publisher's Note}

Springer Nature remains neutral with regard to jurisdictional claims in published maps and institutional affiliations.

Submit your manuscript to a SpringerOpen ${ }^{\mathcal{O}}$ journal and benefit from:

- Convenient online submission

- Rigorous peer review

- Open access: articles freely available online

- High visibility within the field

- Retaining the copyright to your article

Submit your next manuscript at $\boldsymbol{\wedge}$ springeropen.com 